\title{
Toward a More Structured Crime Modelling Method
}

\author{
Hashem Dehghanniri \\ Department of Security and Crime Science \\ University College London \\ 35 Tavistock Square, London, WC1H 9EZ \\ h.dehghanniri.12@ucl.ac.uk
}

\author{
Hervé Borrion \\ Department of Security and Crime Science \\ University College London \\ 35 Tavistock Square, London, WC1H 9EZ \\ h.borrion@ucl.ac.uk
}

\begin{abstract}
Scripts have been used in different disciplines to characterize how individuals conceptualize the conduct of goaloriented tasks. Cornish introduced this modelling approach to the field of environmental criminology as a more systematic way to identify offenders' decisions during the commission of crime. Despite the growing number of articles about crime scripts, there is limited information about the scripting process itself. In particular, there is no publication describing all of the activities involved in the scripting of crime in a comprehensive manner. As a result, the procedural aspects of physical and cybercrimes are predominantly modelled using intuitive rather than structured methods. To fill in this gap, the current study introduces the concept of crime script lifecycle and examine the stages involved in crime scripting process. Following a bottom-up approach, the research involved searching for information relevant to the production of crime scripts and synthesizing the results into a conceptual model. The resulting description of the crime scripting process should improve crime scripting practice, and create a roadmap for future research in this field.

Index Terms - crime script, crime requirements, business process model, modus operandi.
\end{abstract}

\section{INTRODUCTION}

Situational Crime Prevention (SCP) aims 'to reduce opportunities for specific categories of crime by increasing the associated risks and difficulties and reducing the rewards' [1]. This crime reduction approach is usually implemented by modifying environmental elements, processes and policies, and has been used successfully in tackling a variety crimes, including cybercrime [2], fraud [3], identity theft [4], theft [5], and drug manufacturing [6].

Cornish [7] emphasised reducing crime requires taking a crime-specific approach, drawing on detailed knowledge of crime commission processes. To identify and analyse those processes, he proposed to adopt a script-theoretic approach that emerged from the field of psychology.

Schank and Abelson [8] defined script as "a structure that describes appropriate sequence of events in a particular context. [...] It is a predetermined, stereotyped sequence of actions that defines a well-known situation". Scripts are mental structures that organise information about a sequence of predictable actions, locations, and roles that constitute events [9].
TABLE I. Computer abuse crime script - from Overcoming the insider by Willison and Siponen [10]

\begin{tabular}{|l|l|}
\hline \multicolumn{1}{|c|}{ Scene } & \multicolumn{1}{c|}{ Crime Script Function } \\
\hline Preparation & Deliberately gaining access to the organization \\
\hline Entry & Already authorised as employee \\
\hline Pre-Condition & Wait for employees absence from offices \\
\hline Instrumental Pre-Condition & Access to colleagues' computers \\
\hline Instrumental Initiation & Access programmes \\
\hline Instrumental Actualization & False customer account construction \\
\hline Doing & Authorization of fictitious invoices \\
\hline Post-Condition & Exit the application \\
\hline Exit & Exit the system \\
\hline
\end{tabular}

By applying the scripting approach to the crime commission process, analysts can represent 'very complex forms of crime by breaking down the crime commission process into different steps' [6]. Providing 'a way of highlighting the procedural aspects of crime' [7], crime scripts can then aid analysts in identifying logical explanations for the occurrence of problematic (i.e. harmful and/or rule-breaking) events. In practice this involves representing relevant activities occurring at different stages of the crime [11].

In addition crime scripts provide a better understanding about the requirements that are required by the offenders in the process of committing crime [7]. Crime scripts also can be used to identify requirements of security measures/systems, where they highlight the potential situations for applying interventions to disrupt the crime commission process [12].

Table I shows a crime script found in Willison and Siponen [10]. This script characterises the steps offenders follow to defraud an organisation.

Recently, Leclerc [13] and Ekblom and Gill [14] have drawn attention to the growing interest in crime scripting amongst researchers. However, there is, to our knowledge, no published crime study that contains a comprehensive description of the entire crime scripting process and the activities within it. For this reason, providing guidelines to support analysts in the use of a more systematic crime scripting method could potentially enhance the quality of crime scripts, improve the result of crime analysis, and support the design of more suitable security measures.

Some of the activities involved in the crime scripting process have been addressed by several authors of crime scripts: (1) Willison [15] and Brayley, Cockbain, and Laycock [16] 
provided details about the data needed to generate a crime script, where they listed some typical data sources that were used in police investigation, and argued the need for gathering complementary data, (2) Cornish [7] and Ekblom and Tilley [17] included some details about the components of a crime script by listing those components, (3) Beauregard, Proulx, Rossmo, Leclerc, and Allaire [18], and Cornish and Clarke[19] illustrated scripts using different visualisation model-e.g. narratives, tables, or flowcharts-, and (4) Borrion [12], Hutchings and Holts [20], and Dehghanniri, Letier, and Borrion [4] suggested the need for assessing crime scripts.

Some of these publications contain information about identifying data, identifying components of crime scripts, selecting visualisation model, or assessing crime script. However, these details have not been synthesised, integrated or organised as a whole and coherent framework, which motivated this article.

This research identified the activities that form the crime scripting process, as described by different scripters. The resulting description should allow analysts to better understand what makes for a good crime script, and support the development of a roadmap for future research in this field.

This report continues with a section describing the method used to search the literature and map the proposed crime scripting process Section III presents the result and details the constituting activities identified in the reviewed studies. Section IV describes how the proposed model is verified. Finally Section $\mathrm{V}$ summarises the finding and highlights the practical benefits of the research along with directions for further work.

\section{THE METHOD}

This study is part of a larger on-going systematic review about crime script that involved searching all the articles containing the keyword 'crime script' or citing Cornish's seminal article published in 1994 [7]. Our initial search returned 473 studies, including $83(18 \%)$ containing details about the crime scripting process. The activities required to generate a crime script were identified in those articles. The information found was then compiled together and reviewed to determine whether certain activities should be clustered together (when they were considered semantically similar), or alternatively split into multiple activities (when one activity referred to more than one sub-activity). An initial process model was then created, taking into account the presence of order dependencies between all pairs of activities. The process model was also verified by the authors. This involved assessing whether (i) any important activity had been omitted, comparing the listed activities and the information extracted from the reviewed publications) and (ii) there was any logical flaw, considering whether the different steps could be carried out using the information provided by the previous steps. Several iterations of the above method were conducted to address issues identified during the verification stage.

\section{CRIME SCRIPTING PROCESS MODEL}

Figure 1 represents the crime scripting model generated using the aforementioned method. As shown in this Figure, the model comprises eight stages. Not all these stages are neces- sarily required or used in generating a crime script; they can be omitted or repeated as appropriate.

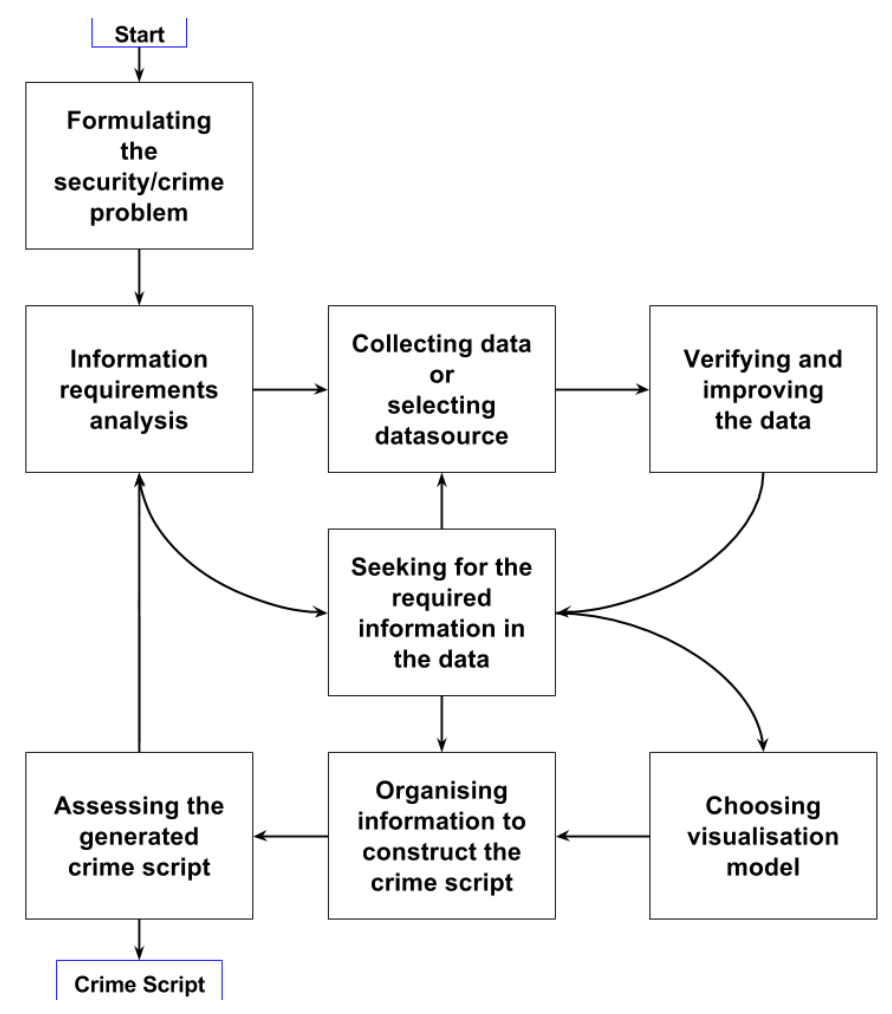

Fig. 1. Crime scripting process model.

\section{1) Formulating the Problem}

In the first instance, the crime phenomenon to be modelled is identified (e.g., burglary). In this stage, analysts should also specify how the resulting model will be used. This is because what is expected from a crime script depends on its application. For example, a crime script created to support the design of a burglary prevention measure may need to be more detailed than one used to assess the risk of a burglary occurring at a given place.

\section{2) Information requirements}

The purpose of the second stage is to derive the requirements concerning the information to include in the crime script (based on the goal of the application). The output of this phase is critical to the quality of the future script as it informs the data collection stage. The information requirements can be divided into two categories: (i) those specifying what types of states, events or activities should be modelled and (ii) those specifying what aspects of those states/events/activities should be detailed. As an example, let us consider a study previously published by the authors [4]. First, after identifying the application of the crime scripts (i.e., assessing the potential effects of different interventions on a particular type of identity theft), we considered the purpose of the script, and concluded that it should represent successful attacks (e.g., sequences of actions that would result in identify theft despite the presence of the authentication system) as well as attacks that are unsuccessful as a direct or indirect effect of the measure. Second, we decided that the el- 
ements to model should be the actions contributing to the attack, those conducting them, the resources involved, and how the latter were used during the attack.

- Requirements concerning states, events and activities: Cornish [7] made suggestions about the events that should appear in crime scripts. He pointed to 'knowledge about procedural aspects of and procedural requirements of crime commission' and information about 'offenders' subjective accounts of crime commission' as the required information for crime scripting. In many studies, the events to include in the crime script were often defined through two questions: What happened that is relevant to the crime? and How it happened? [21, 22]

- Requirements concerning components: Following Schank and Abelson's [8] work, Cornish [7] introduced a list of crime script components: 'scenes, paths, actions, roles, props, and locations'. Scenes are high level components of scripts that can be used for organising the structure of the scripts [23]; they were used in several studies to model the stages of the crime commission process [7, 23]. Studies also identified components such as actors and locations $[6,24]$. In addition, Tompson and Chainey [23] pointed to the description of the required skills, resources, and the effort involved in carrying out the crime process.

\section{3) Data Source Selection}

Once the information requirements are specified, analysts should identify the source of the data from which this information will be extracted. Most of the reviewed studies rely on secondary data sources, including court data [6] and offender testimonies in police reports $[25,26]$. Some of them also gathered primary data as a complementary source such as Brayley, Cockbain, and Laycock [16].

\section{4) Verifying and Improving the Data}

In this step, the quality of the available data is assessed and improved where appropriate. Crime scripts are often built using secondary data sources that do not necessarily encompass all the relevant aspects of the crime script, and their reliability may be limited. In this case, better information can be obtained using more data. For example, if the initially selected data source is not complete enough, the use of multiple secondary data sources or collection of complementary data can be envisaged to improve completeness [16]. As an example, Basamanowicz and Bouchard [27] used court proceedings as their main source of data, but also employed 'secondary data sources to verify and supplement the court case documents'.

\section{5) Information Extraction}

This step aims to identify and extract information from the available data. For this, a targeted search can be performed based on the specified information requirements. Among the previous studies some authors used a structured method to achieve this. For example, Cornish and Clarke [19] and Tompson and Chainey [23] used a template for identifying the information to appear in the final script. They first determined the main scenes of the crime events, then they searched for detailed information related to the each of them.

6) Selecting a Visualisation Model
Considering the application and users of the crime script, and the available information, a visualisation model is selected to represent the final script. Three visualisation models feature in the reviewed literature: tables, flowcharts, and narratives. Most of the reviewed studies relied on a single visualisation model although some of them used a mixture of models [28, 29].

7) Organising Information

After identifying the source of information and selecting the visualisation model, the extracted information must be organised to construct the final crime script. In this step, the information is also reviewed and re-worded to improve the script's readability and consistency.

8) Evaluating the Generated Crime Script

This is the last step of the crime scripting process. The generated script should be assessed based on a selected list of criteria (e.g. accuracy, traceability) [12]. Although the need for assessing crime scripts was mentioned in several studies $[4,12$, $20]$, none of the reviewed studies explicitly addressed this.

\section{VERIFICATION}

The proposed stages and their organisation (as presented in Figure 1) is based on the authors' understanding of crime scripting process. For example, assessment of crime script has to be performed after a first version of the crime script is produced; extracting information should be done after identifying the data source, so it came after identifying data stage; etc.

A verification phase was conducted involving two crime scripters as participants, and collecting information to determine whether (i) the model is an accurate representation of the process they previously followed to construct crime scripts; (ii) any activity has been missed, (iii) any unnecessary activity was included in the model, and (iv) the organisation of the activities is sound.

\section{Note to the reviewers: We are finalising the verification phase and will include the results in this section.}

\section{CONCLUSION}

This article is a first attempt to provide an overall description of the process used to generate high quality crime scripts, including a description of the different stages and their logical dependencies. This crime scripting process model was created to support researchers and practitioners in generating crime scripts and reporting the results. It should also support reviewers in evaluating the methods described in future articles, for example, by contributing to identify missing or poorly documented stages.

This model was inspired by publications in the fields of business process modelling and software engineering lifecycle. For example the first step of our proposed model (i.e., formulating the problem) was not explicitly been considered by the 
existing crime scripting studies. However, it was included in our model, which was inspired from similar models, e.g. software engineering or risk analysis where this activity aims to define the problem and applications' objectives; it is used as the basis and direction of the other stages. Without doing this step, it cannot be clear we should generate the crime script? Or what are the objectives of the application?

To improve the scripting process and enhance the quality of the final scripts, more research in this field of study is required. In particular, methods should be provided and evaluated that could help to construct crime scripts more systematically, and assess whether the generated scripts satisfy the requirements of their application.

\section{ACKNOWLEDGMENT}

This work received funding from EPSRC [EP/G037264/1] as part of UCL's Security Science Doctoral Training Centre, and the EU H2020 research framework for project PRIME [608354].

\section{REFERENCES}

[1] R. V. G. Clarke, Situational crime prevention: Criminal Justice Press, 1997.

[2] M. R. Soudijn and B. C. T. Zegers, "Cybercrime and virtual offender convergence settings," Trends in organized crime, vol. 15, pp. 111--129, 2012.

[3] M. Levi, "Organized fraud and organizing frauds Unpacking research on networks and organization," Criminology and Criminal Justice, vol. 8, pp. 389-419, 2008.

[4] H. Dehghanniri, E. Letier, and H. Borrion, "Improving security decision under uncertainty: A multidisciplinary approach," in Cyber Situational Awareness, Data Analytics and Assessment (CyberSA), International Conference on, 2015, pp. 17.

[5] K. Gentry, "Apple Picking: The Rise of Electronic Device Thefts in Boston Subways," Safety and Security in Transit Environments: An Interdisciplinary Approach, p. 39, 2015.

[6] Y.-N. Chiu, B. Leclerc, and M. Townsley, "Crime Script Analysis of Drug Manufacturing In Clandestine Laboratories Implications for Prevention," British journal of criminology, vol. 51, pp. 355--374, 2011.

[7] D. B. Cornish, "The procedural analysis of offending and its relevance for situational prevention," Crime prevention studies, vol. 3, pp. 151--196, 1994.

[8] R. C. Schank and R. P. Abelson, Scripts, plans, goals, and understanding: An inquiry into human knowledge structures: Psychology Press, 1977.

[9] M. Bennett, The Child as Psychologist: An introduction to the development of social cognition: Harvester Wheatsheaf New York, 1993.

[10] R. Willison and M. Siponen, "Overcoming the insider," 2006.
[11] B. Leclerc and D. Reynald, "When scripts and guardianship unite: A script model to facilitate intervention of capable guardians in public settings," Security Journal, 2015.

[12] H. Borrion, "Quality assurance in crime scripting," Crime Science, vol. 2, p. 6, 2013.

[13] B. Leclerc, "12 New developments in script analysis for situational crime prevention," Cognition and Crime: Offender Decision Making and Script Analyses, p. 221, 2013.

[14] P. Ekblom and M. Gill, "Rewriting the Script: CrossDisciplinary Exploration and Conceptual Consolidation of the Procedural Analysis of Crime," European Journal on Criminal Policy and Research, pp. 1--21, 2015.

[15] R. Willison, "Understanding the offender/environment dynamic for computer crimes," Information Technology \\& People, vol. 19, pp. 170-186, 2006.

[16] H. Brayley, E. Cockbain, and G. Laycock, "The value of crime scripting: deconstructing internal child sex trafficking," Policing, vol. 5, pp. 132--143, 2011.

[17] P. Ekblom and N. Tilley, "Going equipped," British Journal of Criminology, vol. 40, pp. 376--398, 2000.

[18] E. Beauregard, J. Proulx, K. Rossmo, B. Leclerc, and J.-F. Allaire, "Script analysis of the hunting process of serial sex offenders," Criminal Justice and Behavior, vol. 34, pp. 1069--1084, 2007.

[19] D. B. Cornish and R. V. Clarke, "2. The rational choice perspective," Environmental criminology and crime analysis, p. 21, 2008.

[20] A. Hutchings and T. J. Holt, "A Crime Script Analysis of the Online Stolen Data Market," British Journal of Criminology, vol. 55, pp. 596--614, 2015.

[21] J. L. De Bie, C. J. De Poot, and J. P. Van Der Leun, "Shifting Modus Operandi of Jihadist Foreign Fighters From the Netherlands Between 2000 and 2013: A Crime Script Analysis," Terrorism and Political Violence, pp. 1--25, 2015.

[22] S. Jacques and W. Bernasco, "7 Drug dealing," Cognition and Crime: Offender Decision Making and Script Analyses, p. 120, 2013.

[23] L. Tompson and S. Chainey, "Profiling illegal waste activity: using crime scripts as a data collection and analytical strategy," European Journal on Criminal Policy and Research, vol. 17, pp. 179--201, 2011.

[24] A. Hiropoulos, J. D. Freilich, S. Chermak, and G. R. Newman, "10 Cigarette smuggling and terrorism financing," Cognition and Crime: Offender Decision Making and Script Analyses, p. 186, 2013.

[25] M. S. De Vries, "Converted firearms: a transnational problem with local harm," European journal on criminal policy and research, vol. 18, pp. 205--216, 2012.

[26] D. N. Khey and V. A. Sainato, "Examining the correlates and spatial distribution of organizational 
data breaches in the United States," Security Journal, vol. 26, pp. 367--382, 2013.

[27] J. Basamanowicz and M. Bouchard, "Overcoming the Warez paradox: online piracy groups and situational crime prevention," Policy \& Internet, vol. 3, pp. 1-25, 2011.

[28] B. Leclerc, R. Wortley, and S. Smallbone, "Getting into the script of adult child sex offenders and mapping out situational prevention measures," Journal of research in crime and delinquency, p. 0022427810391540, 2011.

[29] J. R. Osborne and J. A. Capellan, "Examining active shooter events through the rational choice perspective and crime script analysis," Security Journal, 2015. 